\title{
PENGARUH PEMBELAJARAN DARING TERHADAP HASIL BELAJAR KOGNITIF MAHASISWA PADA MATA KULIAH LIMNOLOGI
}

\author{
Sepita Ferazona ${ }^{1 *}$, Suryanti ${ }^{2}$ \\ Pendidikan Biologi, Universitas Islam Riau, Jl. Kaharudin Nasution No. 113, \\ Pekanbaru, Riau, Indonesia \\ *Email:sepitabio@edu.uir.ac.id
}

\begin{abstract}
Abstrak
Penelitian ini bertujuan untuk melihat kemampuan hasil belajar kognitif Mahasiswa pada mata kuliah Limnologi selama Selama Pandemik Covid-19. Penelitian ini telah dilaksanakan bulan Mei- Juli Tahun Ajaran 2019/2020, di universitas Islam Riau, Fakultas Keguruan dan IImu Kependidikan Prodi Biologi, Sampel penelitian ini terdiri dari satu kelas, penentuan sampel dengan dengan menggunakan teknik sampling purposive. Penelitian ini menggunakan jenis metode penelitian kualitatif deskriptif. Penulis tidak membuktikan atau menolak hipotesis yang telah direncanakan. Akan tetapi penulis mengolah data dan mengkaji permasalahan dalam bentuk deskripsi yaitu tidak dalam bentuk angka. Penelitian ini menggunakan teknik pengumpulan data wawancara dan dokumentasi yang berisi data hasil pemahaman kognitif siswa beserta nilai mahasiswa semester 4 kelas A. Hasil belajar kognitif mahasiswa diperoleh pada kategori sangat baik dengan persentasi $53,33 \%$ dan baik dengan persentase $46,66 \%$. Hal ini membuktikan bahawa hasil belajar kognitif mahasiswa pada mata kuliah limnologi Selama Pandemik Covid-19 memperoleh hasil yang sangat baik dan baik.
\end{abstract}

Kata kunci : Daring, Hasil Belajar Kognitif, Limnologi

\section{Abstract}

This study aims to see the ability of students' cognitive learning outcomes in the Limnology subject during the Covid-19 Pandemic. This research was conducted in April-July 2019/2020 Academic Year, at Riau Islamic University, Faculty of Teacher Training and Education, Biology Study Program. The sample of this study consisted of one class, the samples were determined using purposive sampling technique. This research uses descriptive qualitative research methods. The author does not prove or reject the hypothesis that has been planned. However, the authors process the data and study the problem in the form of a description, which is not in the form of numbers. This study used interview data collection techniques and documentation which contained data on the results of students 'cognitive understanding along with the grade 4 grade A students' scores. Student cognitive learning outcomes were obtained in the very good category with a percentage of $53.33 \%$ and good with a percentage of 46.66 . This proves that the cognitive learning outcomes of students in the limnology subject during the Covid-19 Pandemic obtained excellent and good results.

Keywords: Online, Cognitive Learning Outcomes, Limnology

\section{Pendahuluan}

Perkembangan ilmu pengetahuan dan teknologi (IPTEK) telah membawa perubahan pesat dalam aspek kehidupan manusia, perkembangan tersebut telah mengubah paradigma manusia dalam mencari dan mendapatkan informasi semakin mudah. Pekerjaan yang semula dilakukan manusia secara manual kini dapat 
digantikan dengan mesin (Hartono, 2012:1). Hal ini menuntut manusia untuk berpikir lebih maju dalam segala hal agar tidak dianggap tertinggal. Salah satu bidang yang cukup berarti dalam perkembangan IPTEK adalah pendidikan. Pendidikan merupakan proses komunikasi dan informasi antara dosen kepada mahasiswa, media sebagai sarana penyajian ide, gagasan dan materi pendidikan serta siswa itu sendiri.

las (Almeida \& Simoes, 2019). Pembelajaran daring merupakan sebuah inovasi pendidikan yang melibatkan unsur teknologi informasi dalam pembelajaran. Menurut Mustofa et al (2019) bahwa Pembelajaran daring merupakan sistem pendidikan jarak jauh dengan sekumpulan metoda pengajaran dimana terdapat aktivitas pengajaran yang dilaksanakan secara terpisah dari aktivitas belajar. pembelajaran daring diselenggarakan melalui jejaring internet dan web 2.0 (Alessandro, 2018), artinya bahwa penggunaan pembelajaran daring melibatkan unsur teknologi sebagai sarana dan jaringan internet sebagai sistem. Pembelajaran daring telah banyak dilakukan dalam konteks perguruan tinggi, terbukti dari beberapa penelitian yang menjelaskan hal tersebut (Crews \& Parker, 2017; Mather \& Sarkans, 2018), pembelajaran daring memberikan manfaat dalam membantu menyediakan akses belajar bagi semua orang, sehingga menghapus hambatan secara fisik sebagai faktor untuk belajar dalam ruang lingkup kelas (Riaz, 2018), bahkan hal tersebut dipandang sebagai sesuatu yang efektif untuk diterapkan khususnya dalam perguruan tinggi, akan tetapi menurut Pilkington (2018) tidak bisa dipungkiri bahwa tidak semua pembelajaran dapat dipindahkan ke dalam lingkungan pembelajaran secara online.

Coronavirus Diseases 2019 (Covid-19) adalah penyakit jenis baru yang belum pernah diidentifikasi sebelumnya pada manusia, pada tanggal 30 Januari 2020 WHO telah menetapkan sebagai kedaruratan kesehatan masyarakat yang meresahkan dunia (Zhou et al., 2020). Pandemi Covid-19 menjadi persoalan multidimensi yang dihadapi dunia, hal tersebut juga dirasakan dampaknya dalam sector pendidikan yang menyebabkan penurunan kualitas belajar pada peserta didik (Sahu, 2020), masa darurat pandemik ini mengharuskan sistem pembelajaran diganti dengan pembelajaran daring agar proses pembelajaran tetap berlangsung (Sintema, 2020), hal ini jelas mengubah pola pembelajaran yang mengharuskan guru dan pengembang pendidikan 
untuk menyediakan bahan pembelajaran dan mengajar siswa secara langsung melalui alat digital jarak jauh (United Nations, 2020).

Proses pembelajaran harus tetap dilakukan pada setiap pendidikan Formal, Universitas Islam Riau mewajibkan setiap dosen untuk melakukan pembelajaran secara daring dengan tujaun proses komunikasi dan informasi tetap antara dosen dan mahasiswa tetap jalan, baik informasi materi materi perkuliahan maupun informasi yang bersifat pribadi. Dengan dilakukan proses pembelajaran daring Mahasiswa tetap semangat dalam mengerjakan tugas atau melaksanakan kuliah via Whatshap, Clasroom dan Goggle Meet.

Hasil wawancara yang dilakukan dengan Mahasiswa, 95\% tetap mengikuti pembelajaran daring dan mengerjakan tugas yang diberikan oleh dosen. Mata kuliah Limnologi merupakan cabang ilmu pengetahuan yang mempelajari tentang sifat struktur perairan daratan yang meliputi mata air, sungai, danau, kolam, dan rawa-rawa, baik yang berupa air tawar maupun air payau. Selain itu, dikenal oseanologi yang mempelajari tentang ekosistem laut. Materi ini membuat mahasiswa bekerja keras mencari sumber yang dapat memberi informasi mengenai Limnologi.

Hasil penelitian sebelumnya yang dilakukan oleh Fitriyani (2020) hal ini dapat dikatakan bahwa ditengah pandemic covid-19 yang melanda dunia, hal tersebut tidak menjadi alasan mahasiswa untuk memiliki motivasi belajar yang tinggi, walaupun dalam pelaksanaannya terdapat kekurang-kekurangan yang ditemukan, akan tetapi tidak ada pilihan lain selain mengoptimalkan pembelajaran daring, karena dalam kondisi darurat seperti ini, hanya teknologilah yang menjadi jembatan dalam transfer ilmu pengetahuan dari dosen ke mahasiswa. Penelitian lainnya yang dilakukan telah menjelaskan bahwa ada hubungan yang signifikan antara kemandirian belajar dengan hasil belajar baik dalam pembelajarn langsung maupun dalam pembelajaran jarak jauh. (Nurhayati, 2019; Tahar \& Enceng, 2006). Dengan keingintahuan yang tinggi maka keinginanan akan mendorong siswa dalam menemukan apa ingin diketahuinya sehingga dapat mempengaruhi hasil belajar (Fauzi et al., 2017). 


\section{Metode}

Penelitian ini telah dilaksanakan pada bulan Mei - Juli Tahun Ajaran 2019/2020 di universitas Islam Riau, Fakultas Keguruan dan IImu Kependidikan Prodi Biologi. Penelitian ini menggunakan jenis metode penelitian kualitatif deskriptif. Penulis tidak membuktikan atau menolak hipotesis yang telah direncanakan. Akan tetapi penulis mengolah data dan mengkaji permasalahan dalam bentuk deskripsi yaitu tidak dalam bentuk angka. Metode penelitian kualitatif merupakan suatu penelitian yang hasilnya tidak diperoleh melalui prosedur statistik atau metode kuantifikasi yang lain (Anggito dan Setiawan, 2018: 8-9). Subjek dalam penelitian ini, penulis menggunakan Quota Sampling. Quota Sampling adalah teknik untuk menentukan sampel dari populasi yang mempunyai ciri-ciri tertentu sampai jumlah (kuota) yang diinginkan. Subjek yang diteliti merupakan kelompok yang sudah ditentukan sesuai dengan kuota kelas, yaitu pada mahasiswa semester 4 kelas A tahun pelajaran 2019/2020. Jumlah mahasiswa sebanyak 30 orang. Penelitian ini menggunakan teknik pengumpulan data wawancara dan dokumentasi yang berisi data hasil pemahaman kognitif siswa beserta nilai mahasiswa semester 4 kelas $A$. Pada wawancara ini pihak yang diwawancara diminta pendapat, dan ide-idenya sehingga penulis harus mendengarkan secara teliti dan mencatat apa yang diucapkan dan dikemukakan oleh pihak wawancara. Wawancara dilakukan dengan sistem dalam jaringan melalui aplikasi Whatshap. Data hasil belajar mahasiswa dapat dikategorikan dalam tabel berikut:

Tabel 1. Kriteria Capaian

\begin{tabular}{|c|c|}
\hline $\begin{array}{c}\text { Tingkat } \\
\text { Keberhasilan }\end{array}$ & Kategori \\
\hline$>80$ & Sangat Baik \\
\hline $60-79$ & Baik \\
\hline $40-59$ & Cukup \\
\hline $20-39$ & Kurang \\
\hline$<20$ & Kurang Sekali \\
\hline
\end{tabular}

(Sumber: Aqib, Diniati, Jaiyaroh, dan Khotimah, 2014: 41)

Teknik analisis data yang digunakan pada penelitian ini adalah menurut Miles dan Huberman yang terdiri dari reduksi data (data reduction), penyajian data (data 
display), dan Conclusion Drawing/Verification. Tahap reduksi data merupakan kegiatan merangkum, memilih hal-hal yang pokok, memfokuskan pada hal-hal yang penting, kemudian mencari tema dan polanya hingga membuang yang tidak diperlukan (Sugiyono, 2015: 338). Oleh karena itu, penulis merangkum data yang didapatkan ketika wawancara dengan dokumentasi yaitu memfokuskan pada hal yang penting berdasarkan pemahaman kognitif siswa dan hambatan yang dihadapi ketika pembelajaran limnologi menggunakan video pembelajaran sistem daring. Penyajian data dapat memudahkan penulis untuk memahami apa yang terjadi dengan disajikan dalam bentuk uraian singkat maupun jenis lain. Maka dari itu, penulis mendeskripsikan hasil pengambilan data dalam bentuk uraian. Pada tahap Conclusion Drawing/Verification, data yang diperoleh setelah dilakukan tahapan reduksi data dengan penyajian data, kemudian data tersebut disimpulkan.

\section{Hasil dan Pembahasan}

Hasil wawancara dapat dideskripsikan sebagai berikut: mahasiswa semangat dalam pembelajaran dengan E-Learning dan daring, tugas yang di berikan dosen tidak ada kendala bagi mahasiswa. Awal perkuliahan dosen sudah menjelaskan secara umum materi yang akan disampaikan selama satu semester, kendala libur karena covid makanya pembelajaran di alihkan daring supaya materi tetap juga tersampaikan. Dosen melakukan pengiriman video pembelajaran dan memgirim materi ajar di classroom dan whatshap, hal ini yang membuat mahasiswa merasa proses pembelajaran secara daring tetap semangat. Adapun kriteria pencapaian hasil belajar di peroleh sebagai berikut:

Tabel 2. Hasil belajar kognitif mahasiswa melalui daring

\begin{tabular}{c|c|c}
\hline $\begin{array}{c}\text { Tingkat } \\
\text { Keberhasilan }\end{array}$ & Kategori & Hasil Belajar Kognitif \\
\hline$>80$ & Sangat Baik & $16(53,33)$ \\
\hline $60-79$ & Baik & $14(46,66)$ \\
\hline $40-59$ & Cukup & - \\
\hline $20-39$ & Kurang & - \\
\hline$<20$ & Kurang Sekali & - \\
\hline
\end{tabular}




\begin{tabular}{c|c|c}
\hline $\begin{array}{c}\text { Tingkat } \\
\text { Keberhasilan }\end{array}$ & Kategori & Hasil Belajar Kognitif \\
\hline \multicolumn{2}{c|}{ Jumlah Mahasiswa } & 30 \\
\hline
\end{tabular}

Hasil wawancara dapat dideskripsikan sebagai berikut: Penerapan proses pembelajaran sesuai dengan kesepakatan dosen dan mahasiswa, sehingga proses belajar berjalan dengan Baik, sehingga mahasiswa dapat mengerjakan tugas dengan baik dan bisa menjawab soal tes. Selama pembelajaran daring dosen selalu mengingatkan tugas yang diberikan, membuat siswa semangat untuk mengikuti mata kuliah Limnologi. Alokasi waktu yang digunakan oleh dosen limnology sesuai dengan waktu yang ada di RPS. Kuliah daring juga tidak membosankan bagi mahasiswa karena dosen Limnologi menggunakan kuliah daring dengan aplikasi yang berbeda setiap perkuliahan.

Keaktifan mahasiswa pada saat pembelajaran daring juga sangat baik, terbukti aktifnya mahasiswa pada saat perkuliahan, sehingga mahasiswa memiliki pengalaman dan pemahaman yang baik terhadap mata kuliah limnologi. Dapat dilihat perolehan nilai hasil belajar kogniotif mahasiswa. Pemahaman hasil belajar kognitif mahasiswa berada pada kategori sangat baik dengan persentasi $53,33 \%$ dan baik dengan persentase $46,66 \%$.

Berdasarkan hasil analisis hasil belajar mahasiswa terhadap pembelajaran daring selama masa pandemik covid-19 yang diperoleh dari tabel di atas menunjukkan bahwa mahasiswa program studi Pendidikan Biologi Fakultas Keguruan dan IImu Pendidikan memperoleh hasil belajar yang sangat tinggi terhadap pembelajaran daring selama masa pandemik Covid-19. Masa pandemik covid-19 tidak menghalangi motivasi mahasiswa dalam melakukan kegiatan pembelajaran secara daring. Mahasiswa yang memiliki motivasi belajar tinggi memiliki keinginan untuk memperoleh nilai yang baik sehingga untuk mencapai tujuan tersebut mahasiswa belajar dengan baik dan rajin. Hasil belajar mahasiswa yang tinggi dapat dilihat berdasarkan indikator salah satunya berkaitan dengan konsentrasi, menurut Azizah (2015) bahwa konsentrasi akan membuat siswa memahami materi yang sedang diajarkan hal ini didasarkan karena perhatian akan tertuju pada apa yang sedang menjadi daya tarik siswa. 
Di tengah kedaruratan yang melanda dunia tidak ada pilihan lain selain menerapkan konsep pembelajaran secara daring, menurut Hung et al (2010) bahwa ada beberapa catatan yang harus diperhatikan agar pembelajaran daring tetap optimal yaitu berkaitan dengan kesiapan belajar diantaranya adalah kepercayaan diri terhadap penggunaan computer/internet, pembelajaran secara mandiri, pengendalian pelajar/mahasiswa, motivasi untuk belajar, dan kepercayaan diri terhadap komunikasi secara online. Semangat belajar mempunyai hubungan yang sangat penting pada kegiatan pembelajaran, ini menunjukkan bahwa baik dosen dan mahasiswa harus menunjukkan semangat yang tinggi pada setiap kegiatan pembelajaran, bahkan menurut Siagian (2015) bahwa semangat pendidik dalam mengajar siswa berhubungan erat dengan minat siswa dalam belajar.

Pembelajaran daring memungkinkan mahasiswa memiliki keleluasaan waktu belajar sehingga dapat belajar kapanpun dan dimanapun. Mahasiswa belajar dengan santai karena bisa membuat tugas di mana saja. Selain itu, mahasiswa dapat berinteraksi dengan dosen menggunakan beberapa aplikasi seperti e-classroom, video conference, telepon atau live chat, zoom maupun melalui whatsapp group (Dhull \& Sakshi, 2017). Beberapa penelitian telah menjelaskan bahwa ada hubungan yang signifikan antara kemandirian belajar dengan hasil belajar baik dalam pembelajarn langsung maupun dalam pembelajaran jarak jauh. (Nurhayati, 2019; Tahar \& Enceng, 2006).

\section{Kesimpulan}

Berdasarkan hasil analisis data yang telah dijelaskan sebelumnya, maka dapat ditarik kesimpulan bahwa hasil belajar kognitif mahasiswa melalui daring menunjukkan sangat baik dengan presentase 53,33\% dan baik dengan presentase 46,6. Hal ini dapat dikatakan bahwa ditengah pandemic covid-19 yang melanda dunia, hal tersebut tidak menjadi alasan mahasiswa untuk memperoleh hasil belajar yang tinggi, walaupun dalam pelaksanaannya terdapat kekurang-kekurangan yang ditemukan, akan tetapi tidak ada pilihan lain selain mengoptimalkan pembelajaran daring, karena dalam kondisi darurat seperti ini, hanya teknologilah yang menjadi jembatan dalam mentransfer pengetahuan dari dosen ke mahasiswa. 


\section{Daftar Referensi}

Alessandro, B. (2018). Digital Skills and Competence, and Digital and Online Learning. Turin: European Training Foundation.

Azizah, S. N. (2015). Peningkatan Konsentrasi dan Hasil Belajar IPA melalui Mind Mapping Siswa Kelas V SDN Jomblangan. Jurnal Pendidikan Guru Sekolah Dasar, 4(5), 1-13. https://doi.org/10.1590/s1809-98232013000400007

Crews, J., \& Parker, J. (2017). The Cambodian Experience: Exploring University Students' Perspectives for Online Learning. Issues in Educational Research, 27(4), 697-719.

Dhull, I., \& Sakshi. (2017). Online Learning. International Education \& Research Journal (IERJ), 3(8), 32-34.

Fauzi, A. R., Zainuddin, \& Atok, R. Al. (2017). Penguatan Karakter Rasa Ingin Tahu dan Peduli Sosial melalui Discovery Learning. Jurnal Teori Dan Praksis Pembelajaran IPS, 2(2), 27-36. http://journal2.um.ac.id/index.php/jtppips/\%0AAchmad.

Hung, M. L., Chou, C., Chen, C. H., \& Own, Z. Y. (2010). Learner readiness for online learning: Scale development and student perceptions. Computers and Education, 55(3), 1080-1090. https://doi.org/10.1016/j.compedu.2010.05.004.

Mather, M., \& Sarkans, A. (2018). Student Perceptions of Online and Face-to-Face Learning. International Journal of Curriculum and Instruction, 10(2), 61-76.

Nurhayati, E. (2019). Penerapan Buku Saku dengan Pendekatan Saintifik untuk Meningkatkan Motivasi dan Hasil Belajar Siswa Pasca Gempa Bumi. Jurnal Kependidikan: Jurnal Hasil Penelitian Dan Kajian Kepustakaan Di Bidang Pendidikan, Pengajaran Dan Pembelajaran, 5(2), 94-99. https://doi.org/10.33394/jk.v5i2.1804

Siagian, R. E. F. (2015). Pengaruh Minat dan Kebiasaan Belajar Siswa terhadap Prestasi Belajar Matematika. Formatif: Jurnal IImiah Pendidikan MIPA, 2(2), 122131. https://doi.org/10.30998/formatif.v2i2.93.

Sintema, E. J. (2020). Effect of COVID-19 on the Performance of Grade 12 Students: Implications for STEM Education. Eurasia Journal of Mathematics, Science and Technology Education, 16(7), 1-6. https://doi.org/10.29333/ejmste/7893.

Sugiyono. (2018). Metode Penelitian Kuantitatif, Kualitatif dan R\&D. Bandung: CV Alfabeta.

Pilkington, O. A. (2018). Active Learning for an Online Composition Classroom: Blogging as an Enhancement of Online Curriculum. Journal of Educational 


\section{Technology}

Systems, 47(2), 1-14. https://doi.org/10.1177/0047239518788278.

Tahar, I., \& Enceng. (2006). Hubungan Kemandirian Belajar dan Hasil Belajar pada Pendidikan Jarak Jauh. Jurnal Pendidikan Terbuka Dan Jarak Jauh, 7(2), 91-101.

Zhou, G., Chen, S., \& Chen, Z. (2020). Back to the Spring of Wuhan: Facts and Hope of COVID-19 Outbreak. Frontiers of Medicine, 14(2), 113-116. https://doi.org/10.1007/s11684-020-0758-9. 